\title{
Geological Controls on Brine Discharge in Itumbula Salt Dam within the Rukwa Rift in Momba District, Tanzania
}

\author{
Mwita S. Maswi*, Octavian Minja and Chakutema Batwenge \\ Geological Survey of Tanzania (GST) P. O. Box 903, Dodoma, Tanzania \\ *Corresponding author, e-mail: maswi.mwita@yahoo.com \\ Co-authors'e-mails: octaminja@gmail.com, batwengesadock@yahoo.com
}

Received 7 Aug 2020, Revised 24 Apr 2021, Accepted 3 May 2021, Published May 2021

DOI: https://dx.doi.org/10.4314/tjs.v47i2.12

\begin{abstract}
The Itumbula salt dam of the Rukwa Rift Basin is a depression formed through extraction of spring-derived salt crystals. Brine yield by springs which is the primary cause of significant amounts of salt in the dam required further geological investigations to understand yield controls. In this study, detailed field geological investigations in the salt dam and its surroundings were conducted to ascertain brine discharge controls. These included documentation of lithology and surface manifestations of brine deposition. Geophysical methods (i.e. magnetic and electric surveys) for studying geologic structures associated with brine deposits, and laboratory analysis of cations and anions (e.g. chlorides, bicarbonates or sulphates) essential to characterize composition of waters were also performed. The information on the springs discharge rate was retrieved from the previous studies. The magnetic profile revealed a very low magnetic anomaly across the salt dam, trending NW to SE direction, which is interpreted to be the main structure that controls fluid movements in the dam. Electric resistivity survey results delineated a low resistivity body in the central part of the dam interpreted as porous formation with saline water. Hydro-chemistry of the hot spring brines indicated high levels of sodium and chloride ions contents than magnesium, calcium, potassium, sulphate, and carbonate and bicarbonate ions, interpreted to be mature water with minimal water mixing. The structurally controlled brines of approximately $2.5 \mathrm{~kg} / \mathrm{s}$ are discharged in the study area.
\end{abstract}

Keywords: Geologic Structures, Brine, Salt Production, Momba, Rukwa Basin.

\section{Introduction}

Beyond the wealth of other mineral resources, the Tanzanian segment of the East Africa rift system is dominated with salt lakes having an overall hydro-chemical equilibria governed by $\mathrm{Na}^{+}>\mathrm{K}^{+}>\mathrm{Ca}^{2+} \sim \mathrm{Mg}^{2+}:\left(\mathrm{CO}_{3}{ }^{2-}+\right.$ $\left.\mathrm{HCO}_{3}{ }^{-}\right)>\mathrm{Cl}^{-}>\mathrm{SO}_{4}{ }^{2-} \sim \mathrm{F}^{-}$ionic concentrations (Philip and Mosha 2012). The mechanism of salt accumulation is suggested to rely on thermo-mechanical disintegrative strains of the geochemistry sources; either by rains that chemically interact with rift terrains, hence transport dissolved salts to the lakes and/or hot springs around the shores of the lakes that carry significant salinity loads into the lakes and basin (Philip and Mosha 2012). The salt reserves increase through repetitive evaporation concentrations in seasonal phases.

The Itumbula salt dam is situated in the Lake Rukwa Rift Basin (western Tanzania), within the western branch of the East African Rift System. In the Lake Rukwa Rift Basin, salt is one of the important natural resources that have been exploited since the early $13^{\text {th }}$ century at Ivuna area currently known as Itumbula project area where operations of salt extraction 
are being carried out at a local scale under the Momba District.

The Rukwa Rift Basin is known to have small hot springs that occur near Lake Rukwa, including the Ivuna springs (Figure 1). The springs discharge $2.5 \mathrm{~kg} / \mathrm{s}$ of $\mathrm{NaCl}$ at $\mathrm{T}=60^{\circ} \mathrm{C}$ $(\mathrm{pH}=8)$, while the heat discharge is estimated to be 0.3 MW (Hochstein et al. 2000). The Itumbula area has been ear-marked to likely have a potential for brine-derived salt resulting from the presence of hot springs and its position in the East African Rift System (Figure 1).

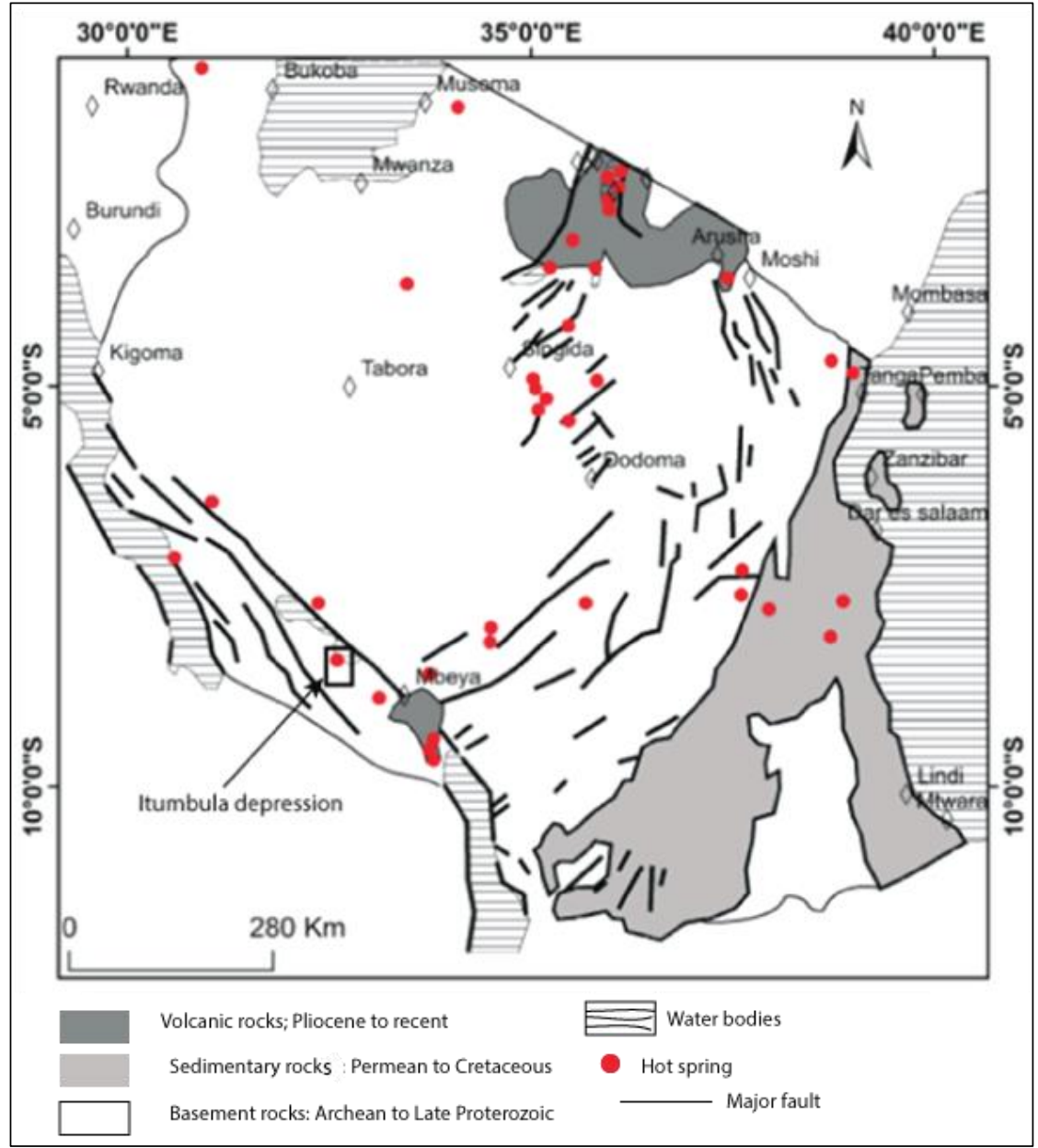

Figure 1: A map of Tanzania showing occurrence of hot springs, and location of the study area, Itumbula depression in southwestern Tanzania (modified from Mnjokava et al. 2015).

Springs in Itumbula have been diverted into evaporation ponds to sustain a small, local salt industry in Momba District, and are reported to discharge gases with almost no carbon dioxide $\left(\mathrm{CO}_{2}\right)$ gas but consisting of mainly nitrogen $\left(\mathrm{N}_{2}\right)$ gas (James 1967). It is known that salt (sodium chloride; $\mathrm{NaCl}$ ) occur naturally in the seas and underground deposits whereas it can be harvested directly either from sea water or natural brine or from rock salt deposit formed by evaporation of earlier seas that left a layer of rock salt commonly known as halite (Briggs 1996). 
Brine discharge control at Itumbula salt dam is still inconclusive despite increasing trends of local scale brine production at the area. The latter has prompted a plan to upgrade salt extraction operations from small scale to medium scale operations. It is this plan that has further prompted geoscientific investigations in the area aiming at precisely delineating geological controls of brine production, including its hydro-chemical properties. Multidisciplinary investigations were conducted and involved geologic, geophysics and hydro-geochemistry to figure-out how the geology of the area influences brine discharge. The findings of this study are expected to lay grounds for further exploration and prospecting phases, including decision to carry out resource estimation and calculation that will finally guide in setting priority sites.

\section{Geological Background}

The Rukwa Rift Basin is completely enclosed, fed by an internal drainage system with Lake Rukwa covering large part of the basin floor (Wescott et al. 1991). The study area overlies the Paleoproterozoic Ubendian Belt that is predominantly characterized by large masses of metamorphosed mafic igneous rocks complex ranging from meta-anorthositic to meta-gabbroic batholiths (Boniface 2020). At various places surrounding the study area, the metamorphosed silicic granitoids were documented (Boniface 2020) (Figure 2).

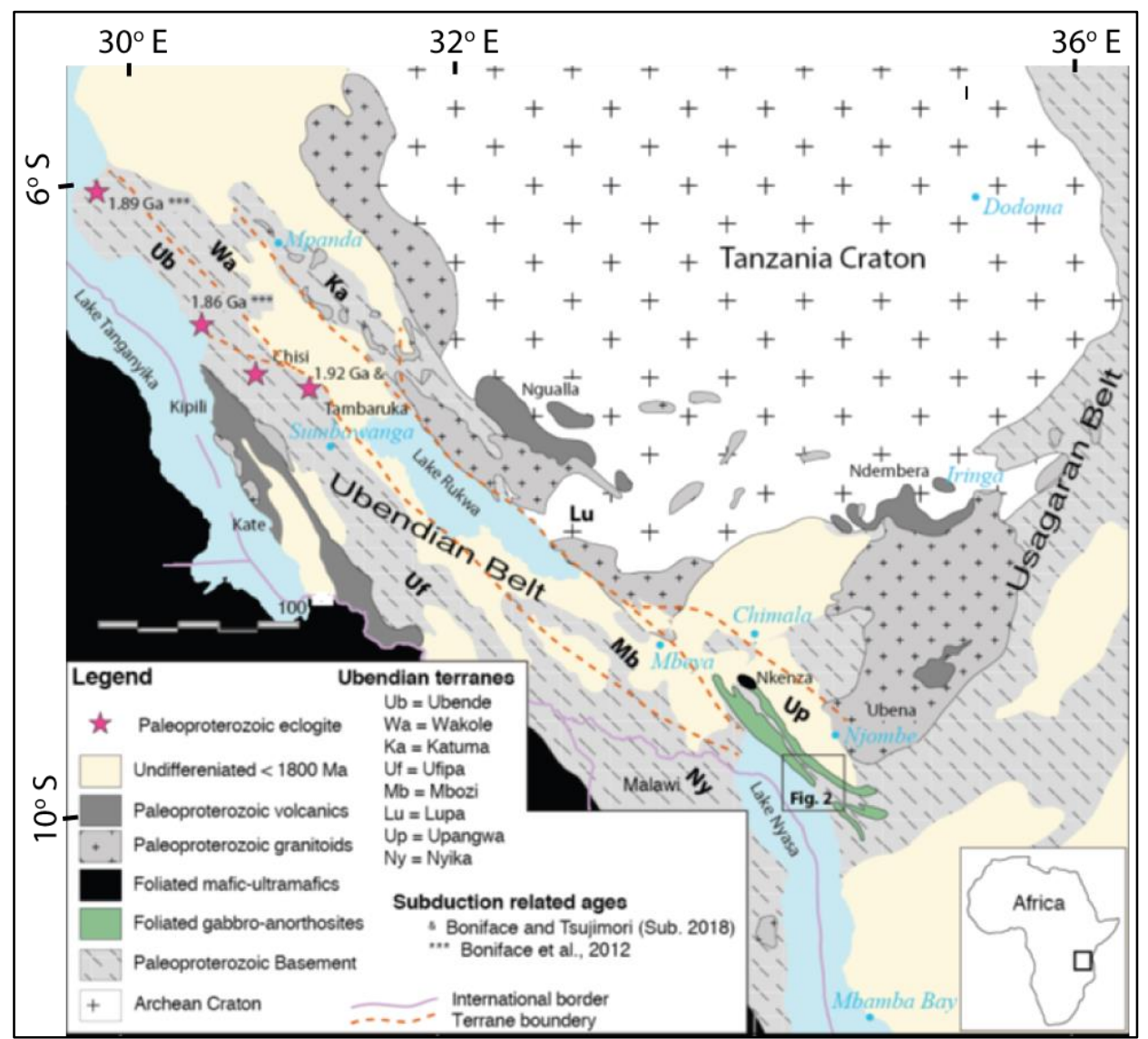

Figure 2: Regional geological map of the southern Ubendian Belt showing the Rukwa Rift (Adopted from Boniface 2020). 
Ages of the rocks of the Rukwa Rift Basin were obtained from biostratigraphic analysis and they reflect a Late Permian to Late Pliocene-Holocene range (Wescott et al. 1991). In the study area, three main groups of gneisses forming the basement system overlain by poorly consolidated Cretaceous red beds and soft sediments (sands and clays) of Quaternary period (Spurr 1951).

The Itumbula salt dam is on the floors of the Rukwa trough near the southwest corner of the Lake Rukwa and $10.5 \mathrm{~km}$ from the Lake shore and in a flat bottomed steep-sided, roughly rectangular depression about $457 \mathrm{~m}$ in length, and $244 \mathrm{~m}$ across (Spence 1953). Around the eastern half of the depression is an irregular semicircle of smooth hillocks of the metamorphosed mafic igneous rocks rising to 9 $\mathrm{m}$ above its floor and $5 \mathrm{~m}$ above the level of the surrounding plain, whereas the walls of the depression are composed of soft sand and clay being eroded by water action aided by landslips (Spence 1953). The interpreted lineaments from regional scale low resolution aeromagnetic and shuttle Radar Topography Mission data, indicate the major lineaments that cross the study area trends NW-SE following the major trend of the western arm of the East African Rift System (Figure 1).

\section{Materials and Methods \\ Materials}

A number of typical geologic and geochemical field gears were used during geologic and geochemical surveys, including a global positioning system (GPS), geological hammer, magnetic pencil, geologic compass, portable temperature/pH meter, plastic sampling bottles and distilled water for cleaning plastic bottles before sampling. The geophysical equipment were magnetometer and IP instrumentation for the magnetic and resistivity surveys, respectively.

\section{Methods}

Field geologic mapping and hydrogeochemical survey

This study applied geologic, geophysical and geochemical approaches. Field geologic mapping involved documenting lithologies around the Itumbula salt dam with approximate size of $420,000 \mathrm{~m}^{2}$. Traverses were planned along N-S direction in order to cross cut the major structures. As part of geological mapping demarcation of surface manifestations of the brine aquifer zone and geologic structural analysis were performed. Furthermore, mapping was conducted to determine the relationship between known hot springs in the area.

Hydro-geochemical surveys involved measurements of $\mathrm{pH}$ and temperatures in hot springs and surroundings by using portable $\mathrm{pH} /$ temp probe;-to quickly examine the ambient temperature of the area, hot springs temperatures and salinity properties of water through $\mathrm{pH}$ analysis. Hot spring water samples were collected directly from the hot spring discharge zones using plastic bottles by immersing them below the surface to ensure a free-flow from the sample spot. Before sampling, sample bottles were cleaned using distilled water. The hot spring water samples aimed to constrain hydro-geochemistry of hot springs, examine water mixing up by determining salinity distribution around the salt dam. The hydro-geochemical analysis of cations and anions of the collected water samples was carried at the laboratory of the Geological Survey of Tanzania, Dodoma.

\section{Magnetic surveys}

The aim of magnetic surveys was to determine the magnetic susceptibility of the area and inference on subsurface structural features. The structures are very important because they indicate permeability that may probably demarcate fracture basement aquifer system from which brine percolates. Magnetic data were acquired using two magnetometers GSM-19TW Proton Precision Magnetometers, 
as rover and base station for recording diurnal variations. Both magnetometers were mounted with Global Positioning System (GPS) receiver for recording position or location of data collection. The magnetometer measured the total magnetic intensity with accuracy of +/0.1 gamma (nT), and the GPS provided the position of a point with respect to the Earth's surface and elevation of the point above sea level. The minimum rate of data sampling was three (3) samples per second.
The data was then downloaded by GEM Link software and processed using Geosoft Oasis Montaj software for noise reduction, map processing and filtering such as analytical signal, horizontal and vertical derivatives. The acquisition of ground total magnetic intensity data in the project area were based on two key parameters: line spacing of $50 \mathrm{~m}$ between profile lines and sampling interval measurements of continuous recording (Figure 3). A total of $8 \mathrm{~km}$ lines were investigated.

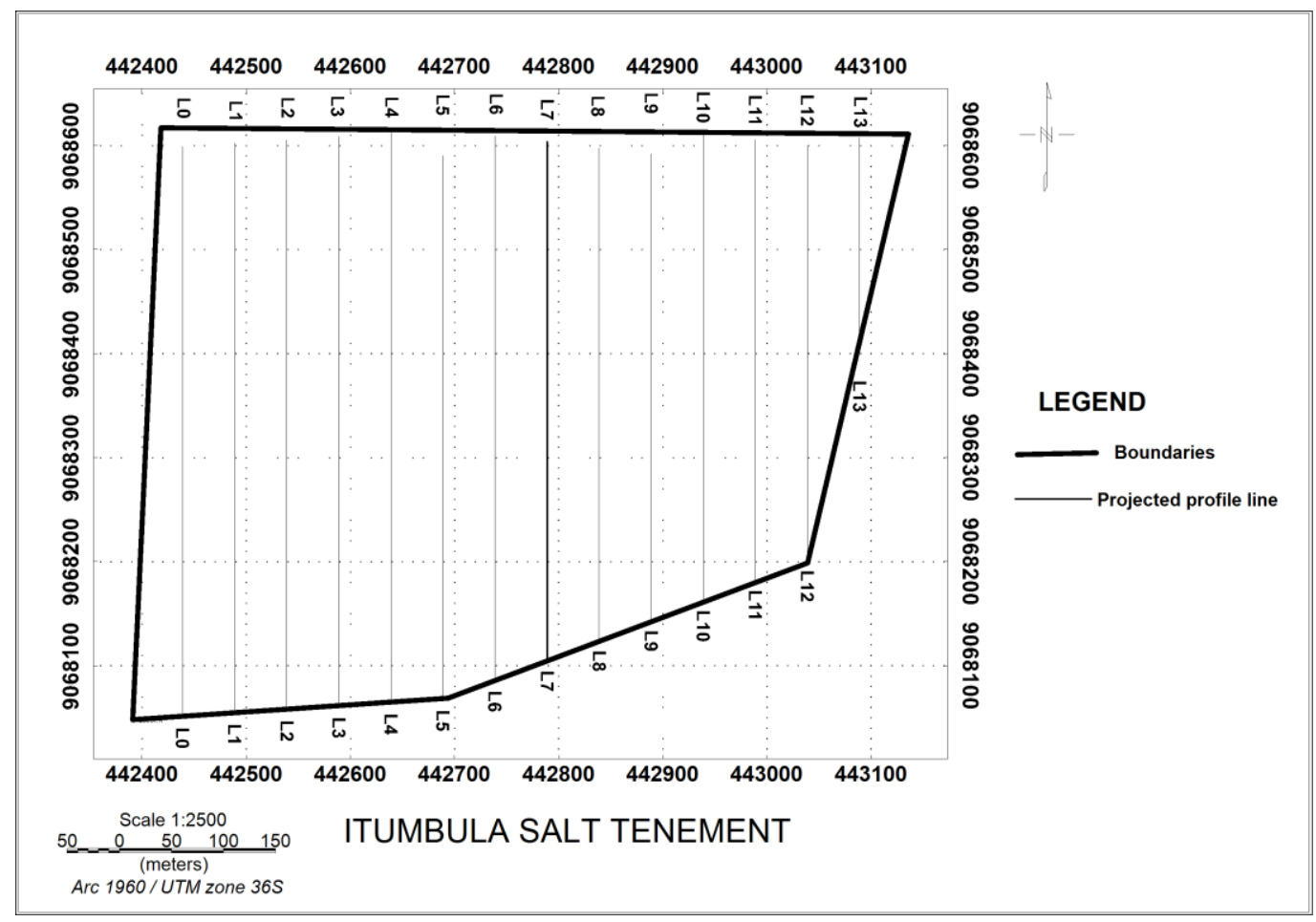

Figure 3: Map showing survey profile lines at Itumbula salt dam.

\section{Electrical survey method}

The induced polarization (IP) electric-survey method was conducted so as to determine electrical properties of the subsurface rocks. A total of $8 \mathrm{~km}$ lines were surveyed using dipole- dipole array, with line spacing and sampling interval of $50 \mathrm{~m}$ (Figure 4). Large spacing between electrodes aimed to increase penetration depth. The set up of equipment is shown in the Figure 4. 


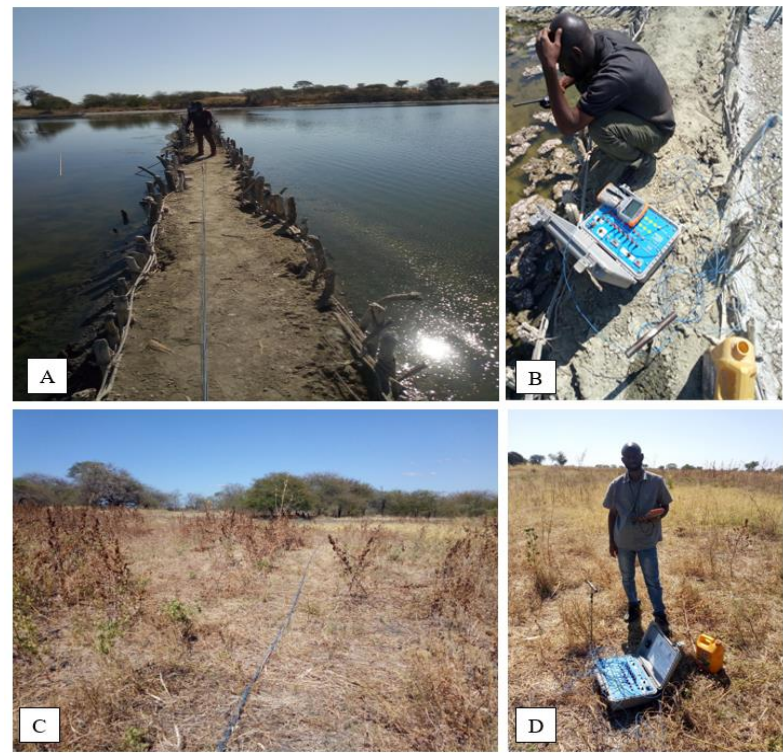

Figure 4: Field photos showing the layout of IP cables (A and C), receiver setup and data acquisition (B and D).

\section{Geochemical analysis of hot springs samples}

All geochemical analyses were performed at the Geological Survey of Tanzania (GST) geochemical laboratory. The purpose was to classify hot spring waters into either chloride, sulfate or bicarbonate water types using a ternary plot diagram. Analyses included chemical compositions of the hot spring samples, i.e., cations $\left(\mathrm{Na}^{+}, \mathrm{Ca}^{2+}\right.$ and $\left.\mathrm{Mg}^{2+}\right)$ and anions $\left(\mathrm{CO}_{3}{ }^{2-}, \mathrm{HCO}_{3}^{-}, \mathrm{SO}_{4}{ }^{2-}\right.$ and $\left.\mathrm{Cl}^{-}\right)$ concentrations. Analyses involved treatment of the hot spring water samples with dilute nitric acid $\left(\mathrm{HNO}_{3}\right)$. This was done to prevent precipitation and adsorption, to minimize microbial degradation to container walls, as well as to digest the samples before carrying out atomic absorption spectroscopy (AAS) by destroying the matrix which may interfere with atomization process.

The analyses were done by AAS for $\mathrm{Na}^{+}$, $\mathrm{Ca}^{2+}$ and $\mathrm{Mg}^{2+}$ cations, chloride electrode and probe for $\mathrm{Cl}^{-}$anion, titrations for $\mathrm{CO}_{3}{ }^{2-}$ and $\mathrm{HCO}_{3}{ }^{-}$anions. The utraviolet light was used to analyse $\mathrm{SO}_{4}{ }^{2-}$ anion. Ternary plot was used to distinguish different types of thermal waters whereas immature water was expected to give an indication of mixing relationships plotting in the $\mathrm{Ca}^{2+}$ or $\mathrm{Mg}^{2+}$ cations and $\mathrm{HCO}^{3-}$ anion regions. Mature waters that indicate no or mininal mixing were expected to plot in $\mathrm{Na}^{+}$ cation and $\mathrm{Cl}^{-}$anion regions (Stober and Bucher 2013). This analysis was further expected to point out any existing genetic relationships between data points including maturity, mixing lines or environment of origin (Lajwe 2014).

\section{Results}

This part presents the field observations and geology of the area, hydro-geochemistry of the area, and geophysical findings.

\section{Geological field results}

Geologically, the area is dominated with irregular hillocks of the metamorphosed mafic igneous rocks rising up to $10 \mathrm{~m}$ above its floor. The walls of the depression are composed of soft sand and clay being eroded by water action. From field observations, it looked like the materials from erosion were gradually filling up the dam gradually making it wider and shallower. 
Three major groups of springs that trend in the NW-SE are documented at the middle part of the depression, two of which produce slightly saline hot water with temperature values ranging between 30 to $34{ }^{\circ} \mathrm{C}$ and $\mathrm{pH}$ of 8.5 to 9 . However, a few other small spring bubbles are noted in the southeastern part of the dam with slightly low temperature up to 26 ${ }^{\circ} \mathrm{C}$. Therefore, the Itumbula salt dam contains

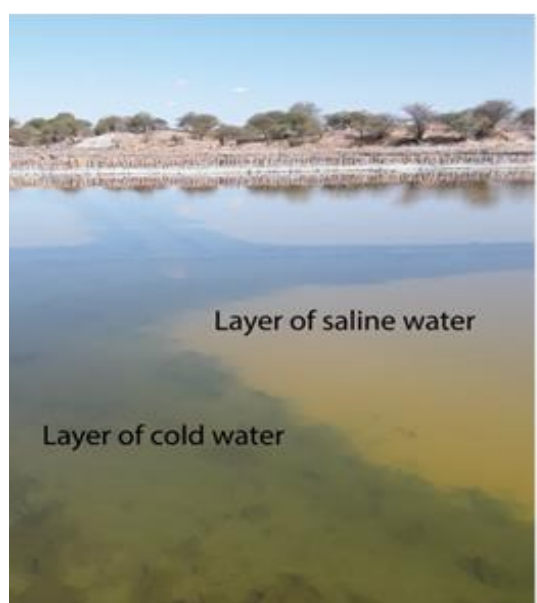

Figure 5: Influx of cold water at Itumbula salt dam that may probably result into a delay of salt crystal formation in the area.

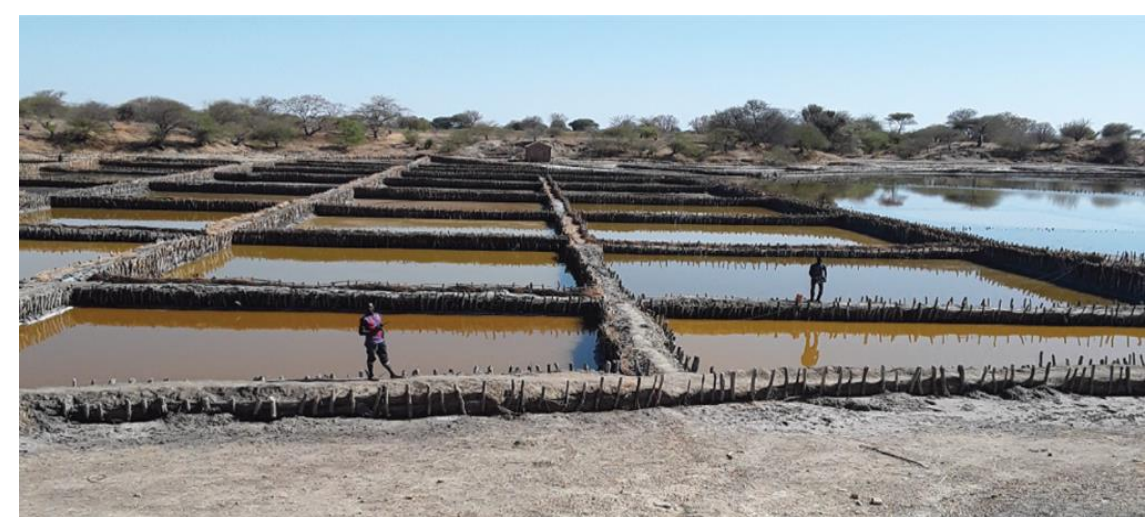

Figure 6: Salt evaporation ponds at Itumbula dam which is the major means of salt extraction.

\section{Hydro-geochemical results}

Results from analyses of cations $\left(\mathrm{Na}^{+}, \mathrm{Ca}^{2+}\right.$ and $\left.\mathrm{Mg}^{2+}\right)$ and anions $\left(\mathrm{CO}_{3}{ }^{2-}, \mathrm{HCO}_{3}{ }^{-}, \mathrm{SO}_{4}{ }^{2-}\right.$ and $\mathrm{Cl}^{-}$) of hot springs and salt dam waters are presented in Table 1 . The results indicated

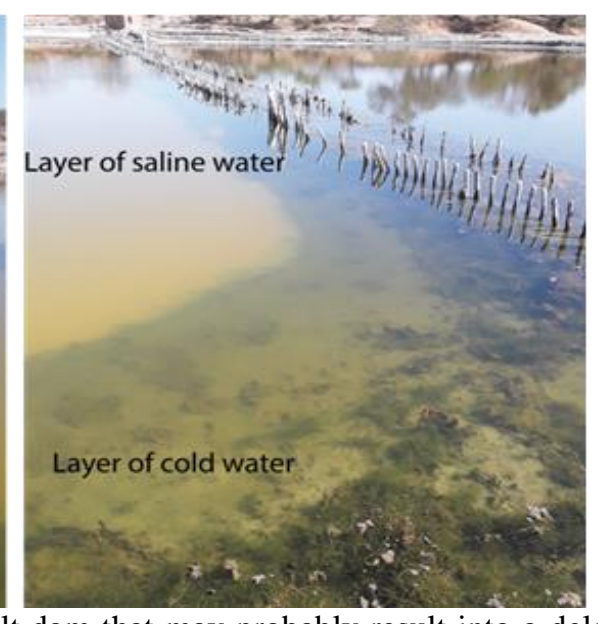

several cold springs in the salt dam, particularly in the southeastern part (Figure 5). Further observations revealed that, salt extraction at the Itumbula area is mainly by solar evaporation method whereby the natural brine evaporates up to the saturation point in the open basin by action of sun and wind (Figure 6).

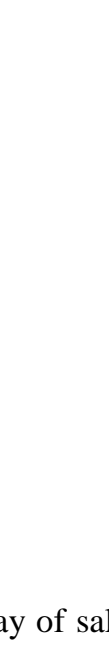


Tanz. J. Sci. Vol. 47(2), 2021

Table 1: Laboratory results of collected samples

\begin{tabular}{llllllll}
\hline $\begin{array}{l}\text { Sample } \\
\text { No. }\end{array}$ & $\begin{array}{l}\mathrm{Na}^{+} \\
(\mathrm{ppm})\end{array}$ & $\begin{array}{l}\mathrm{Ca}^{2+} \\
(\mathrm{ppm})\end{array}$ & $\begin{array}{l}\mathrm{Mg}^{2+} \\
(\mathrm{ppm})\end{array}$ & $\begin{array}{l}\mathrm{Cl}^{-} \\
(\mathrm{ppm})\end{array}$ & $\begin{array}{l}\mathrm{SO}_{4}{ }^{2-} \\
(\mathrm{ppm})\end{array}$ & $\begin{array}{l}\mathrm{CO}_{4}{ }^{2-} \\
(\mathrm{ppm})\end{array}$ & $\begin{array}{l}\mathrm{HCO}_{3}{ }^{-} \\
(\mathrm{ppm})\end{array}$ \\
\hline IVU001 & 18900 & 1599.36 & 225.79 & 16700 & 3839 & 50 & 125 \\
IVU002 & 21000 & 1881.60 & 282.24 & 21700 & 4263 & 75 & 100 \\
IVU003 & 86200 & 3245.76 & 141.12 & 74200 & 4629 & 175 & 75 \\
IVU004 & 273400 & 1646.40 & 112.9 & 14600 & 3610 & 75 & 50 \\
\hline
\end{tabular}

The cations-anions data are presented in $\mathrm{Na}-\mathrm{Mg}-\mathrm{Ca}$ and $\mathrm{Cl}-\mathrm{SO}_{4}-\mathrm{HCO}_{3}$ ternary diagrams in order to show fluid compositions (Figure 7). Samples collected from spring's waters indicated that all cations plot in the sodium region with minimal concentration of calcium,

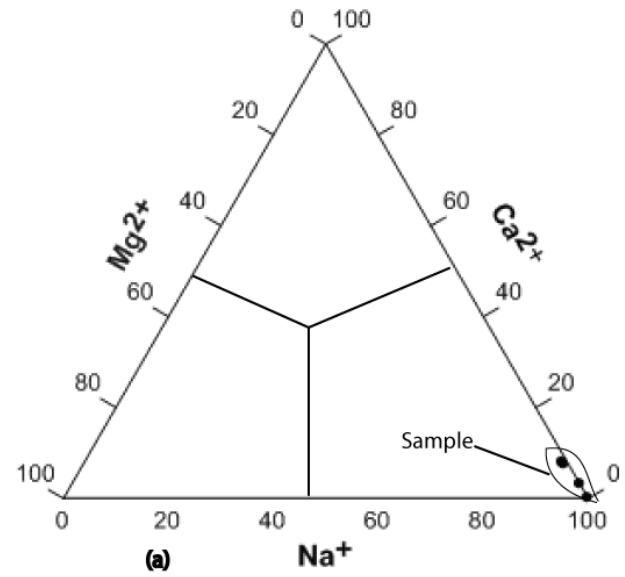

while anions plot in the chlorine area with minimal sulphate water and none of the samples showed affiliations to the regions of magnesium cation and regions of bicarbonate anions.

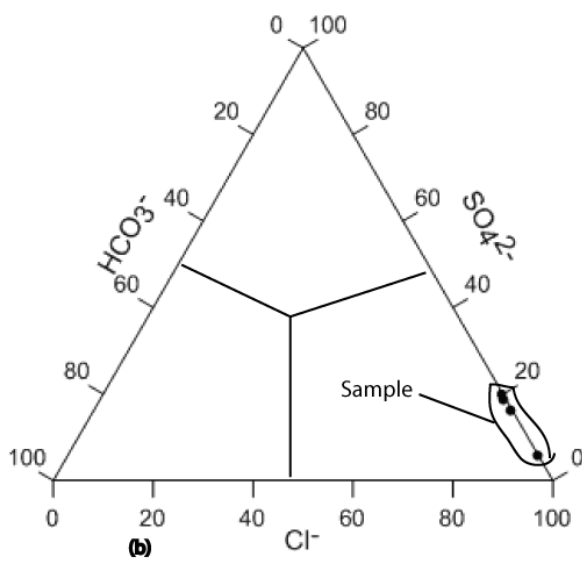

Figure 7: Ternary plot diagrams for cations and anions in Itumbula salt dam (a) cation concentrations, $\mathrm{Na}^{+}$dominate followed by $\mathrm{Ca}^{2+}$ other cations (b) anion concentrations that indicate $\mathrm{Cl}^{-}$be the dominant in the dam followed by $\mathrm{SO}_{4}{ }^{2+}$.

\section{Geophysical results}

Results of the total magnetic intensity are presented in Figure 8. The data show that the area has high and low magnetic anomalies, whereby the low magnetic anomaly (blue colour) is situated between the two high magnetic anomalies (pink colour) in the south and north of the area that trend in NW-SE direction. The white coloured field represents an area from which data was not collected due to inaccessibility.
The southwestern corner of the study area indicates a relatively strong magnetic susceptibility, whereas southeast of the area has a very low magnetic susceptibility (Figure 8 ). It can also be seen that low magnetic signature is falling under hot springs discharge zone and it is trending NW-SE as shown in the total magnetic intensity image (Figure 8). The strength of the magnetic signature is relatively high in the NW than in the SE of the study area. 
Maswi et al. - Geological controls on brine discharge in Itumbula Salt Dam ...

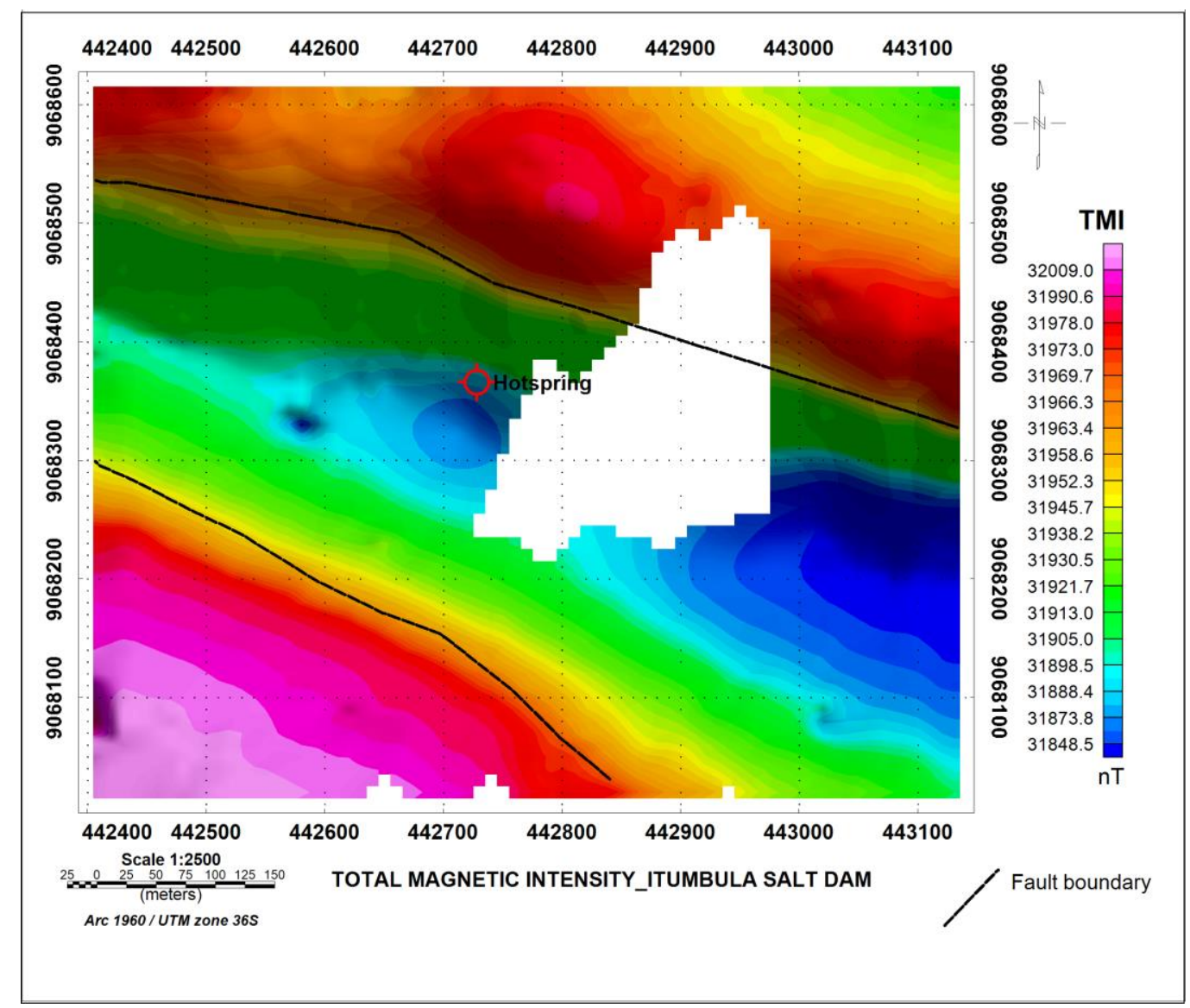

Figure 8: Total magnetic intensity (TMI) map showing areas with high and low magnetic anomalies, a dash line demarcates an area with low magnetic value, the hot spring within the low magnetic signature is indicated with a red dot, and white colour is area not surveyed due to water.

The ground resistivity survey results show high resistive body is indicated by pink colour and low resistive body by a blue colour (Figures 9, 10, 11 and 12). The results for the surveyed profile lines are indicated in Figures 9, 10, 11 and 12. Pseudo section maps (Figure 9) show that the apparent resistivity variations are high along lines 442423 at 9068200 to 9068300 and 9068375 to 9068475 at a depth of more than $100 \mathrm{~m}$, and the lowest apparent resistivity appears at 9068325 to 9068375
(Figure 9a). Line 442473 apparent resistivity is high at 9068200 to 9068400 at a depth of more than $150 \mathrm{~m}$ and low at 9068150-9068475 (Figure 9b). Line 442523 appears high at 9068200 to 9068350 around a depth of more than $150 \mathrm{~m}$ and is low near 9068120 to 9068475 (Figure 9c). The high resistivity is shown by pink colour (zone B), low resistivity is shown by a blue colour (zone A) and moderate is shown by reddish colour (zone C). 

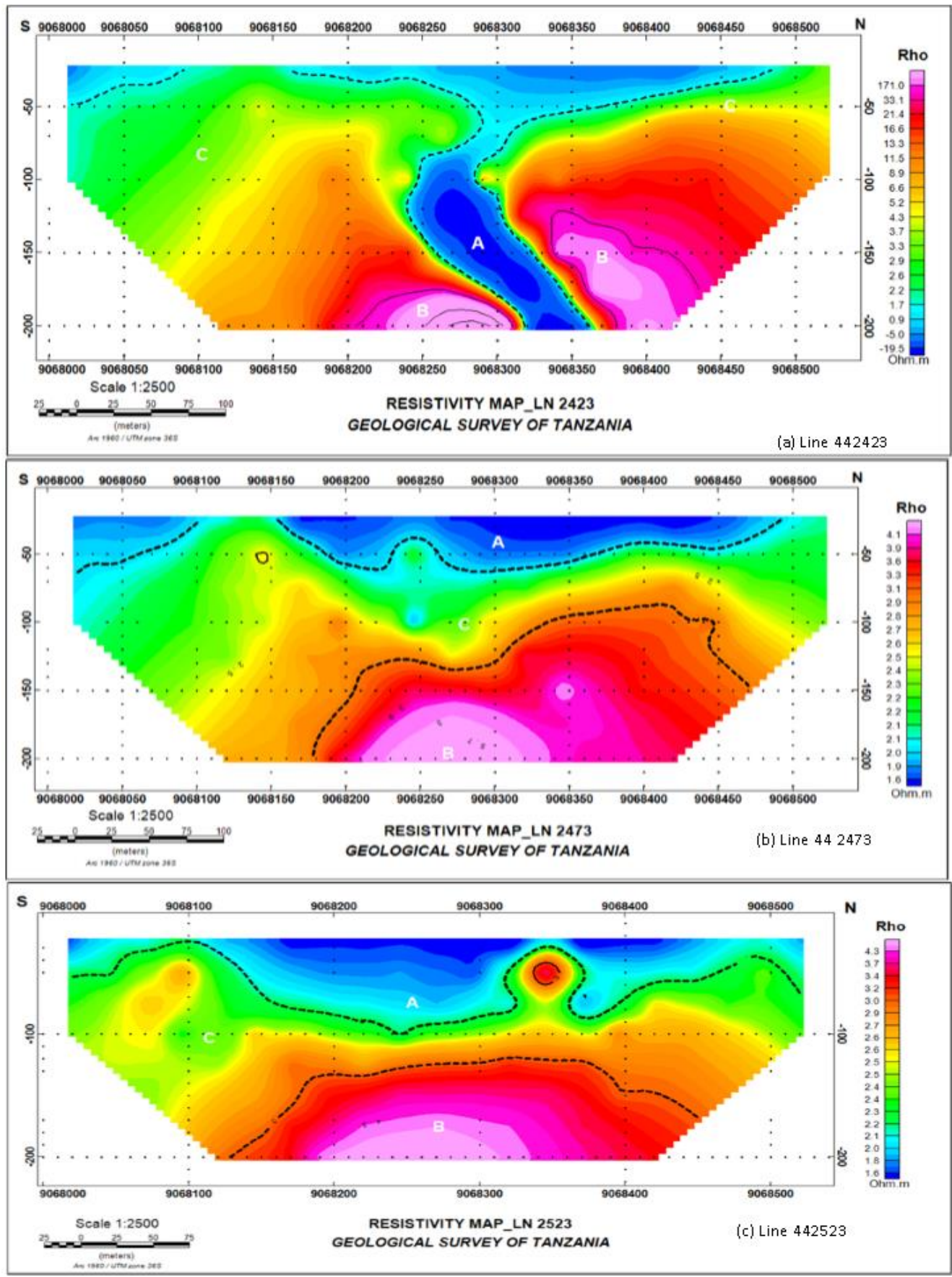

Figure 9: The pseudo section maps; (a) Line 442423; (b) Line 442473 and (c) Line 442523 . The high resistivity is shown by pink colour (zone B), low resistivity by a blue colour (zone A) and moderate is shown by reddish colour (zone $\mathrm{C}$ ). 
Maswi et al. - Geological controls on brine discharge in Itumbula Salt Dam ...

Hot spring is centered in low resistivity body at $442728 / 9068366$ (Figure 10b). In line 442973 high resistivity is observed to appear at 9068040 to 9068150 at depth of more than 120 $\mathrm{m}$ as shown by a pink colour (zone B), while lowest apparent resistivity appears partially in south and mostly in northern side of the profile from 9068150 near surface as shown in blue colour (zone A), moderate resistivity variation covers a large area of the profile (zone C) (Figure 10c).

In Figure 10, the pseudo section of line 443023 shows high apparent resistivity at 9068180 to 9068290 and around 9068350 to 9068530 near a depth of more than $150 \mathrm{~m}$ as shown by pink colour (zone B), while lowest apparent resistivity appears from 9068230 to 9068580 near the surface as shown in blue colour (zone A). Moderate resistivity variation covers a large area of the profile (zone C) (Figure 11a). Line 443123 shows high resistivity at 9068020 to 9068200 around a depth of more than $120 \mathrm{~m}$ as shown with pink colour (zone B), while lowest apparent resistivity appears from 9068360 to 9068480 at a depth of more than $100 \mathrm{~m}$ and near surface at 9068200 to 9068280,9068350 and beyond as shown in blue colour (zone A) with moderate resistivity variation covers a large area of the profile (zone C) (Figure 11b). Line 443123 shows high apparent resistivity at 9068020 to 9068200 and 9068380 to 9068470 around depth of more than $120 \mathrm{~m}$ as shown by pink colour (zone B), while lowest apparent resistivity appears from 9068100 to 9068200 , 9068300 to 9068520 near the surface and from 9068250 to 9068290 at a depth of more than $100 \mathrm{~m}$ at the center of the profile as shown in blue colour (zone A) and moderate resistivity variation covers a large area of the profile (zone C) (Figure 11c). 


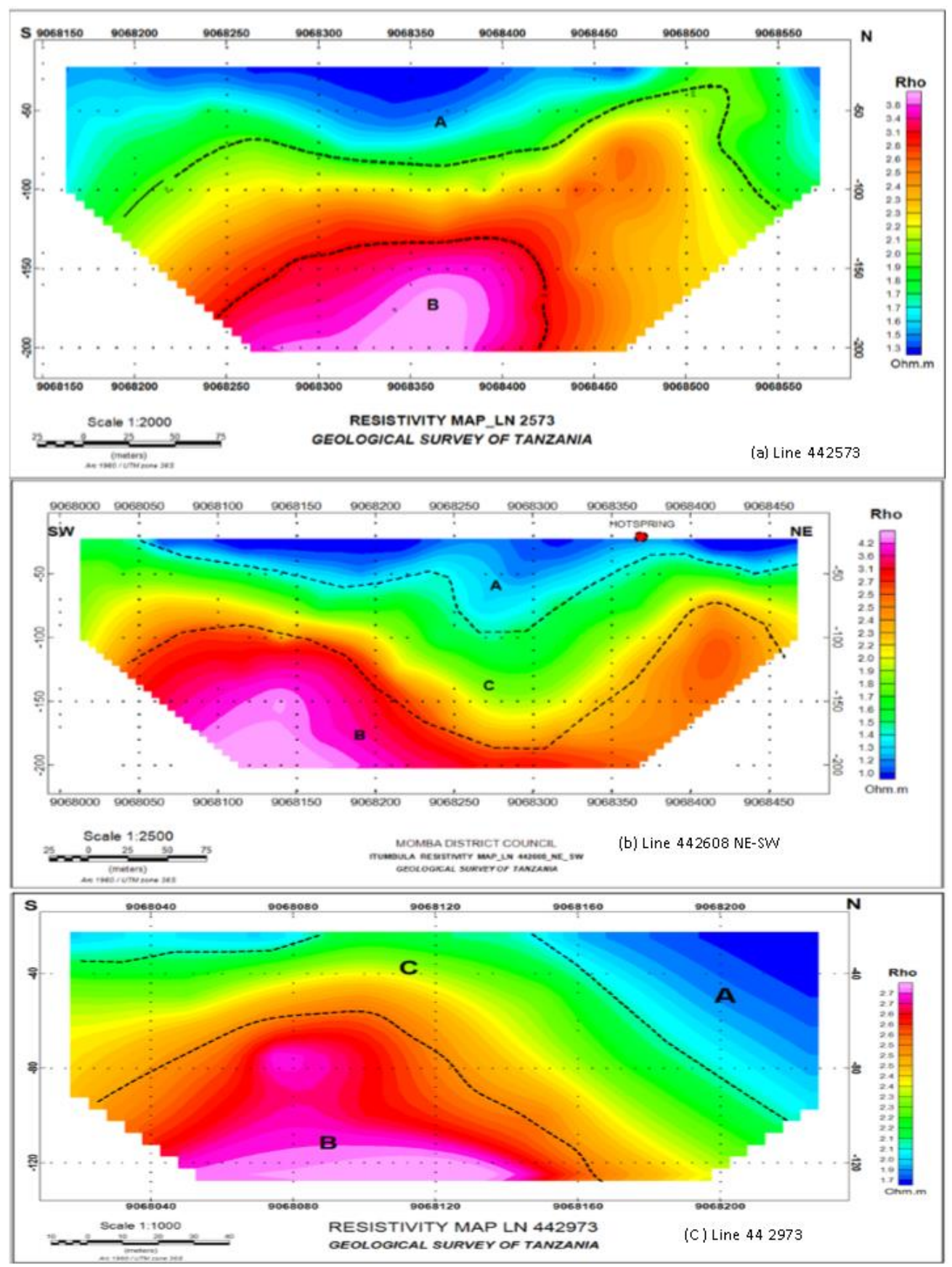

Figure 10: The pseudo section map; (a) Line 442573; (b) Line $442608 \mathrm{NE}-\mathrm{SW}$ and (c) Line 442973. The high resistivity is shown by pink colour (zone B), low resistivity by a blue colour (zone A) and moderate is shown by reddish colour (zone C). 
Maswi et al. - Geological controls on brine discharge in Itumbula Salt Dam ...
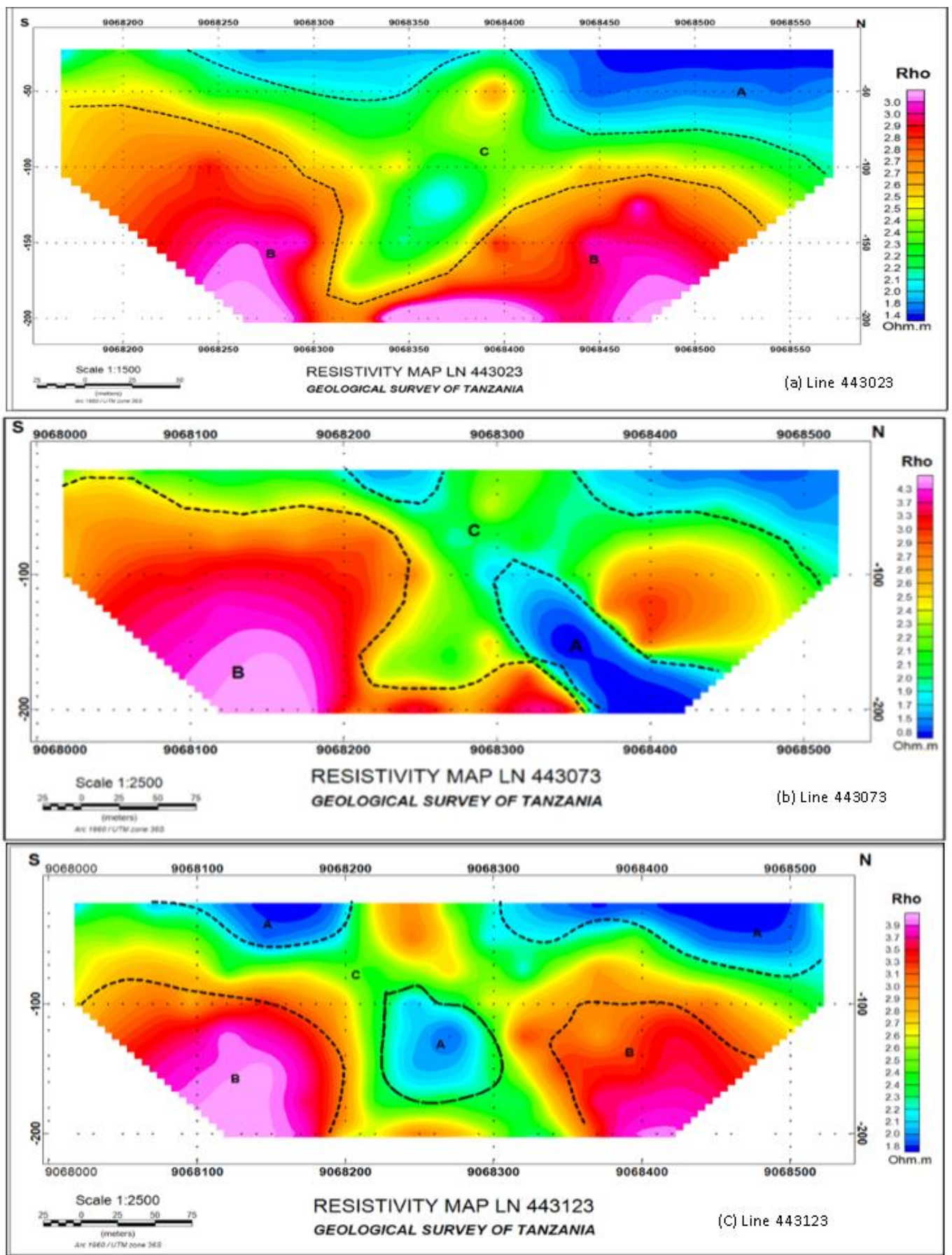

Figure 11: The pseudo section map; (a) Line 443023; (b) Line 443073 and (c) Line 443123. The high resistivity is indicated by pink colour (zone B), low resistivity by a blue colour (zone A) and moderate is shown by reddish colour (zone C). 
The views of the resistivity near the surface at $25 \mathrm{~m}$ depth are shown in Figure 12. It is observed that low resistivity variation covers mostly the northern side of the dam as well as in the middle area towards west. The whitish area is missing the data due to water coverage and the hot spring is centered to zone of low resistivity weak zone.

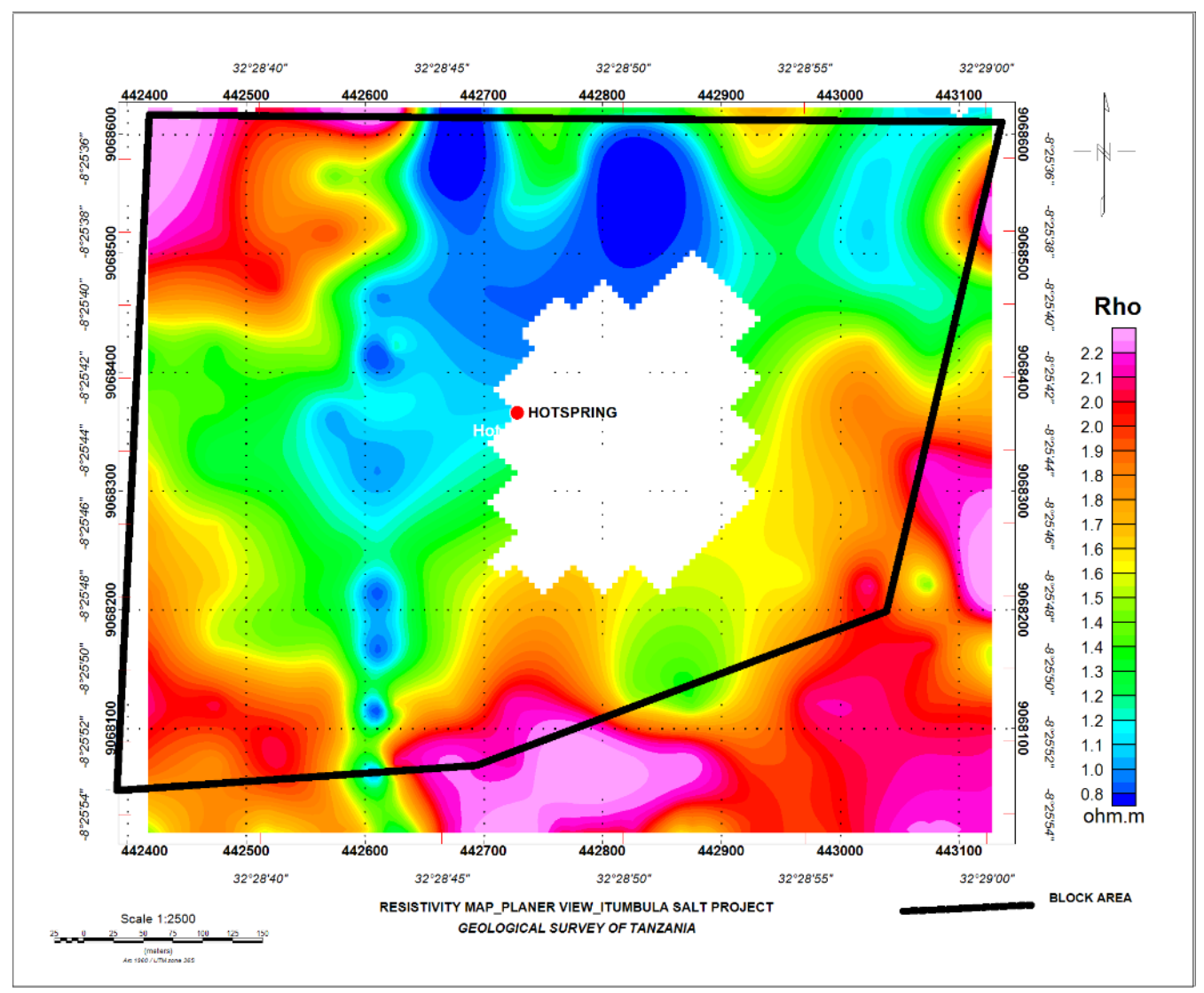

Figure 22: Shows the plan view of the resistivity map at $25 \mathrm{~m}$ depth.

\section{Discussion}

Magnetic surveys have revealed the presence of a structural feature (most likely a fault) that appears to be a recharge channel for hot springs to the dam. This is supported by the occurrence of hot springs whose trends conform to the fault trend (i.e. NW-SE direction). The interpreted linear structure is suggested to act as a conduit for hot springs in the dam, as in a structural interpreted zone/aquifer, the magnetic susceptibility is realized to be low. The trend of the interpreted low ground magnetic body is similar with the main East African Rift System (NW-SE) interpreted from the regional scale low resolution aeromagnetic data that show the Itumbula area to lie within the major structure trending SE.

The low resistivity signatures relate to structures filled with saline water, and hence suggests good conductor marked easily by electrical resistivity. Hot springs mapped in the area seem to concentrate in a low resistive body and they measured $\mathrm{pH}$ values of 8.5 to 9 (all alkaline in nature). Therefore, low resistivity signature in the area is the influence 
of outflow of the brine dominating the salt dam. The hydro-geochemistry of the hot springs and waters collected around the salt dam supports the electric resistivity results, whereby it was observed the area to be enriched with $\mathrm{Na}^{+}$prevailing over $\mathrm{Ca}^{2+}$ and $\mathrm{Mg}^{2+}$. In addition, the hydro-geochemical results indicated chloride waters enriched and depleted with bicarbonate waters, therefore, termed as sodium chloride $(\mathrm{NaCl})$ water (Figure 7). The similar type of chloride salt composition was suggested by Marini (2016) to be mature chloride waters, which tend to be hosted in geothermal reservoirs.

The two ternary plots indicate that hot springs in the area are in the region having $\mathrm{Na}$ $\mathrm{Cl}$ source with and in a higher content of magmatic system containing $\mathrm{NaCl}$ depleted with $\mathrm{CO}_{2}$. The area has a $2.5 \mathrm{~kg} / \mathrm{s} \mathrm{NaCl}$ brine discharge rate and gases with almost no $\mathrm{CO}_{2}$ gas (James 1967, Hochstein et al. 2000). The fluid composition provide the evidence of location and mechanism that there is a less water mixing phenomena in the Itumbula dam because when water arises from a geothermal reservoir to the surface and emerge in form of hot springs, it is usually cooled on the way by conduction, boiling, or mixing with shallow cold water, or by any combination of these three processes (Gendenjamts 2003).

Interpretations made from field observations show that, the Itumbula area contains several cold springs, particularly in the further southern part. A possibility that colder springs tend to dilute hot springs resulting into a delay of salt crystal formation in the salt ponds is suspected in the area. The typical evidence of cold water influx (mixing up) in the salt dam is observed and reported by this study. Inferences made based on field relationship show that, the most likely sustainable recharge system is just nearby Lake Rukwa.

\section{Conclusions and Recommendations}

The Itumbula brine discharge is structurally controlled as revealed by ground magnetic data with very low linear NW-SE trending magnetic signature cross cutting the salt dam. Resistivity survey indicated a conductive body in the dam that is interpreted to be a conduit for $\mathrm{NaCl}$ brine with discharge rate of $2.5 \mathrm{~kg} / \mathrm{s}$ and Lake Rukwa is suggested to be a nearby main sustainable recharge system of the fluid. Moreover, the trend of the linear structure encountered during ground surveys follows that of the East African Rift System. At a regional scale, resolution of aeromagnetic survey has shown that hot springs are all centred in the linear structure.

Despite the potential for economic extraction of brine salt in Itumbula salt dam by considering brine control system, hydrochemistry, discharge rate and recharge system, the current small scale salt extraction method is solar evaporation. This method is easily affected by dilution from external sources such as dilution from cold springs discharge, weather fluctuation and surface runoff inflow.

The study is therefore, recommending further studies on how precisely the dilution can affect the salt crystallization in the dam, including cold spring discharge rates and weather fluctuations which were not considered during this study. However, detailed fluid geochemistry is required to clearly ascertain the origin of brine in the dam as to whether it is magmatic, connate or metamorphic water. Solution-mining method in the area to facilitate quick evaporation from the permeable site and salt crystal formation is suggested instead of solar evaporation method. Furthermore, to confirm the presence of a permeable aquifer identified by the geophysical survey, this study recommends drilling in the area. This exploration technique will be useful in estimating salt water resources by measuring fluid flow rate.

\section{Acknowledgements}

We express our sincere gratitude to the Geological Survey of Tanzania and Momba District administration for the support that enabled successful completion of the geological surveys at Itumbula salt dam. Special thanks should also be extended to Dr 
Cassy Mtelela and Dr Emmanuel O. Kazimoto from University of Dar es salaam Department of Geology, Dr Michael Msabi from University of Dodoma Department of Geology for their decision to engage with Geological Survey of Tanzania to review the earlier version of the manuscript. I would like to express my sincere gratitude to the Chief Executive Officer of the Geological Survey of Tanzania for permitting work execution, paper review in terms of logistics and financial support.

\section{References}

Boniface N 2020 Geochemical characterization of Paleoproterozoic Massif-Type Anorthosite, from the Ubendian Belt, Tanzania. Tanz. J. Sci. 46(1): 61-75.

Briggs P S 1996 Salt Mining in New York: The Ins and Outs of the Solution Mining Industry and Its Significance. Solution Mining Research Institute.

Gendenjamts O 2003 Interpretation of chemical composition of geothermal fluids from Arskógsströnd, Dalvík, and Hrísey, NIceland and in the Khangai area, Mongolia in Geothermal Training Programme, Reykjavík, Iceland. Rep.10.

Hochstein M, Temu E and Moshy C 2000 Geothermal resources of Tanzania in Proceedings World Geothermal Congress, Kyushu - Tohoku, Japan, May 2000.

James TC 1967 Thermal springs in Tanzania. Institution of Mining \& Metallurgy, Transactions, Section B 76(729): B1-B18.

Lajwe G 2014 Comparison characterization and interpretation of geothermal fluid geochemistry in sedimentary environment of
Kibiro, Panyimur, and Öxarfjördur. UNU Geothermal Training Programme, Reykjavik, Iceland. Report, 12.

Marini L 2016 Effective geochemical methods for identifying geochemical systems in western branch of the East African Rift System (EARS). Technical Workshop on the Geologic Development and Geophysics of the Western Branch of the Greater East African Rift System.

Mnjokava T Kabaka K and Mayalla J 2015 Geothermal Development in Tanzania-a Country Update. Melbourne, Australia.

Philip JYN and Mosha DMS 2012 Salt lakes of the African Rift System: A valuable research opportunity for insight into nature's concentrated multi-electrolyte science. Tanz. J. Sci. 38(3): 1-13.

Spence J 1953 Report on Ivuna Salt Pans, DS 69. Geological Survey Division. Dodoma, Tanzania.

Spurr A 1951 The limestone and guano deposits of the Songwe River Area. Geological Survey of Tanganyika, Dodoma.

Stober I and Bucher K 2013 The chemical composition of deep geothermal waters and its consequences for the planning and operating a geothermal power plant. Geothermal Energy (pp. 255-277). Springer, Berlin, Heidelberg.

Wescott W, Krebs W, Engelhardt D and Cunningham S 1991 New biostratigraphic age dates from Lake Rukwa Rift Basin in Western Tanzania. AAPG Bull. 75(7): 1255-1263. 